\title{
Chlamydia and gonorrhoea in pregnant Batswana women: time to discard the syndromic approach? Maria Romoren*1, Johanne Sundby ${ }^{1}$, Manonmany Velauthapillai ${ }^{2}$, Mafizur Rahman ${ }^{3}$, Elise Klouman ${ }^{4}$ and Per Hjortdahl ${ }^{1}$
}

\begin{abstract}
Address: ${ }^{1}$ Institute of General Practice and Community Medicine, Faculty of Medicine, University of Oslo, Box 1130 Blindern, N-0318 Oslo, Norway, ${ }^{2}$ The National Health Laboratory, Ministry of Health, Gaborone, Botswana, ${ }^{3}$ Sexual and Reproductive Health Associates, Gaborone, Botswana and ${ }^{4}$ Norwegian Institute of Public Health, Oslo, Norway

Email: Maria Romoren* - maria.romoren@medisin.uio.no; Johanne Sundby - johanne.sundby@medisin.uio.no; Manonmany Velauthapillai - velamano@hotmail.com; Mafizur Rahman - mafiz@info.bw; Elise Klouman - elise.klouman@fhi.no; Per Hjortdahl - per.hjortdahl@medisin.uio.no

* Corresponding author
\end{abstract}

Published: 16 April 2007

BMC Infectious Diseases 2007, 7:27 doi:10.1 186/1471-2334-7-27
Received: 4 October 2006

Accepted: 16 April 2007

This article is available from: http://www.biomedcentral.com/147/-2334/7/27

(C) 2007 Romoren et al; licensee BioMed Central Ltd.

This is an Open Access article distributed under the terms of the Creative Commons Attribution License (http://creativecommons.org/licenses/by/2.0), which permits unrestricted use, distribution, and reproduction in any medium, provided the original work is properly cited.

\begin{abstract}
Background: Chlamydia and gonorrhoea are major causes of morbidity among women in developing countries. Both infections have been associated with pregnancy-related complications, and case detection and treatment in pregnancy is essential. In countries without laboratory support, the diagnosis and treatment of cervical infections is based on the syndromic approach. In this study we measured the prevalence of chlamydia and gonorrhoea among antenatal care attendees in Botswana. We evaluated the syndromic approach for the detection of cervical infections in pregnancy, and determined if risk scores could improve the diagnostic accuracy.

Methods: In a cross-sectional study, 703 antenatal care attendees in Botswana were interviewed and examined, and specimens were collected for the identification of $C$ trachomatis, $N$ gonorrhoeae and other reproductive tract infections. Risk scores to identify attendees with cervical infections were computed based on identified risk factors, and their sensitivities, specificities, likelihood ratios and predictive values were calculated.

Results: The prevalence of chlamydia was $8 \%$, and gonorrhoea was found in $3 \%$ of the attendees. Symptoms and signs of vaginal discharge did not predict cervical infection, and a syndromic approach failed to identify infected women. Age (youth) risk factor most strongly associated with cervical infection. A risk score with only sociodemographic factors had likelihood ratios equivalent to risk scores which incorporated clinical signs and microscopy results. However, all the evaluated risk scores were of limited value in the diagnosis of chlamydia and gonorrhoea. A cut-off set at an acceptable sensitivity to avoid infected antenatal care attendees who remained untreated would inevitably lead to considerable over-treatment.

Conclusion: Although in extensive use, the syndromic approach is unsuitable for diagnosing cervical infections in antenatal care attendees in Botswana. None of the evaluated risk scores can replace this management. Without diagnostic tests, there are no adequate management strategies for $C$ trachomatis and $N$ gonorrhoeae in pregnant women in Botswana, a situation which is likely to apply to other countries in sub-Saharan Africa. Screening for cervical infections in pregnant women is an essential public health measure, and rapid tests will hopefully be available in developing countries within a few years.
\end{abstract}




\section{Background}

Sub-Saharan Africa has the highest prevalence of gonorrhoea and chlamydia worldwide. These two sexually transmitted infections (STIs) have a major impact on health, particularly in women and neonates [1]. A cervical infection with Neisseria gonorrhoeae or Chlamydia trachomatis can cause serious complications, such as ascending infections, infertility, cervical cancer, spontaneous abortion, premature delivery and low birth weight [2]. Epidemiological and biological studies have shown that ulcerative and non-ulcerative STIs can enhance HIV transmission $[3,4]$.

It should be part of the mandate of the antenatal care programmes to diagnose and treat $C$ trachomatis and $N$ gonorrhoeae, due to their association with maternal, foetal and infant morbidity. In developing countries, diagnosis of cervical infections is limited to the syndromic approach, using the 'vaginal discharge syndrome' (VDS) algorithm. In the early 1990s, the World Health Organization developed syndromic management guidelines as a case management of symptomatic STI patients in countries without laboratory support [5]. Easily recognized symptoms and signs are combined using flowcharts, and patients are treated with two or more antibiotic regimens to cover the majority of, or the most serious, organisms responsible for producing a syndrome. The VDS algorithm for the management of vaginal and cervical infections is far from ideal, and for chlamydia or gonorrhea, this simplified approach is neither sensitive nor specific $[2,5-8]$. Simple, rapid tests for these infections have been requested for more than a decade $[9,10]$, and the continued use of the syndromic approach in the management of cervicitis has been viewed as a temporary solution while awaiting the development of such tests [11].

The majority of women with a cervical infection are asymptomatic [12] and their infection will not be detected by the syndromic approach. As screening with specific diagnostic tests have been out of reach, risk scores based on sociodemographic risk factors, symptoms or signs of infection, urine sticks and microscopy have been explored as screening tools to identify asymptomatic infections among pregnant women. Studies from subSaharan countries have shown variable and unconvincing results $[9,10,13-16]$.

It has become clear that vaginal discharge is poorly predictive of cervicitis, and in order to reduce over-treatment, the WHO recommends the incorporation of risk assessments in the syndromic management of cervical infections [5]. In Botswana, the syndromic approach has recently been revised, and lower abdominal pain was included as a second entry symptom in the VDS algorithm [17]. Treatment for $C$ trachomatis and $N$ gonorrhoeae is reserved for women who present with vaginal discharge or lower abdominal pain and have either a positive risk assessment (age less than 21 years or complaints of yellow discharge) or yellow discharge or cervical mucopus on examination. These new recommendations are based on a non-validated study of female STI patients [18]. Risk factors' association with infection is specific to the population group from which they are extracted $[5,13]$, and a validation of the algorithm in the antenatal care is lacking.

There are two parallel strategies to manage reproductive tract infections (RTIs) in pregnancy in Botswana. In addition to the syndromic management of women with symptoms, all antenatal care attendees are clinically screened for RTIs. The antenatal care guidelines recommend a routine speculum examination at the first antenatal visit, to "exclude genital infections, abnormalities and pelvic tumours" [19]. It is not uncommon for abnormal vaginal discharge to be found in women who are not eliciting symptoms. Asymptomatic pregnant women with signs of vaginal discharge will also be provided with syndromic treatment. Clinical screening bypasses the original entry point of the syndromic algorithms: symptoms which lead to health-care seeking, and it is not within the WHO recommendations.

The aim of this study was to determine the prevalence of $C$ trachomatis and $N$ gonorrhoeae among antenatal care attendees in Botswana, and to assess the validity of the 'vaginal discharge syndrome and lower abdominal pain' algorithm in the diagnosis of cervicitis in pregnancy. We also evaluated the diagnostic accuracy of risk scores based on sociodemographic factors, specific symptoms or signs, or microscopy. The results from Botswana are used to discuss the management of cervicitis in pregnancy in subSaharan Africa.

\section{Methods}

Participating in this study were 703 pregnant women who visited the 13 main facilities providing antenatal care in Gaborone, Botswana: 12 primary health clinics and one outpatient department. A proportionate sample of attendees was recruited from each location. This proportion corresponded to the percentage of all antenatal care attendees in Gaborone who visited that facility during the previous year. Facilities were visited one-by-one by a medical doctor between October 2000 and February 2001. In the majority of clinics, all attendees were included in the study. In the busiest clinics, only a sample of the attendees was included; the selection of attendees in these clinics was incidental. Approximately one out of every four antenatal care attendees in Gaborone was included in the study during the period of data collection. All participants gave written, informed consent. The only exclusion crite- 
rion was the use of antibiotics during the previous two weeks.

A structured interview and information from the patientheld antenatal record were used to obtain data on sociodemographic and behavioural factors, current RTI symptoms, and diagnosis and prescribed treatment for such conditions earlier in the pregnancy. All patients underwent a genital examination; appropriate specimens were collected; and abnormal signs from external and internal genitalia were recorded in detail.

\section{Laboratory analyses}

Urine was checked on site with a dipstick; all other specimens were analysed at the National Health Laboratory in Gaborone. Cervical swabs were obtained for ligase chain reaction (LCR) amplification technology for detection of $C$ trachomatis and $N$ gonorrhoeae. The swabs were placed in $\mathrm{LCx}^{\otimes}$ transport media, transported to the laboratory the same day, and stored at $-20^{\circ} \mathrm{C}$ prior to batch processing. The LCX ${ }^{\oplus}$ Assays (Abbott Laboratories, IL) were performed according to the manufacturer's instructions. A case of $C$ trachomatis or $N$ gonorrhoeae infection was defined as an individual with a positive LCR analysis.

A high vaginal swab for identification of Trichomonas vaginalis was placed in Stuart transport media. Before culturing, a wet-mount was made and examined for the presence of motile trichomonads by light microscopy, $100 \times$ magnification. The swab was then agitated into a bottle of Diamond's modified medium. The bottles were incubated with indicators in Oxoid gaspack jars (3.4 litres, with anaerobic system BR 038B). Wet-mounts from the cultures were examined once a day for five days by light microscopy.

Gram-stained vaginal smears were scored for bacterial vaginosis according to Nugent's criteria [20]. Culture of Candida species was initiated by direct inoculation of a high vaginal swab on Saboraud plates on site, and Gramstained smears and wet-mounts from high vaginal swabs were examined for budding yeast cells and pseudohyphae. A cervical smear was gram-stained to count polymorphonuclear leukocytes per high power field (PMN/HPF).

\section{Statistical analyses and risk scores}

Data were analysed with the statistical package SPSS Version 11 . We performed univariate analyses on all independent variables in our dataset which could be associated with cervical infection. The factors were within four categories: sociodemographic and behavioural factors, symptoms, clinical signs, and microscopy results. The dependent variable "cervicitis" was defined as infection with $C$ trachomatis or $N$ gonorrhoeae, or both. Factors which in the univariate analysis were associated with infection at a 0.2 level (p-value of odds ratio (OR)) were included in multiple logistic regression analyses. We performed multiple logistic regression analyses on sociodemographic factors, symptoms, clinical signs and laboratory results, separately and combined. Due to the high number of variables, the full analysis of different factors' independent association with cervicitis had to be performed in two steps. First, multiple logistic regression analyses for the four variable categories were performed separately. The analysis was then extended to combining the factors from the different categories which were significantly independently associated with cervical infection in the first step.

Three levels of risk scores were computed and retrospectively applied, and each of them were assessed for their usefulness as a diagnostic tool to manage $N$ gonorrhoeae and $C$ trachomatis infections in the antenatal care. The first risk score level consists of only sociodemographic factors. At the second risk score level we added findings from the gynaecological examination. At the third level, we also allowed the results from microscopy of vaginal and cervical smears. Microscopy can be done on site, and thus all three risk score levels - the sociodemographic, the clinical and the microscopy score - can theoretically be performed during an antenatal care visit. The weights for each factor used in the risk scores were based on correspondent multiple logistic regression analysis models. The log of the OR for the variables in the model multiplied by 10 and rounded to the nearest whole number were used as weights for the respective factors in the risk scores [9]. The factors included and their respective weights are shown for each risk score in Table 1.

Receiver Operating Characteristic (ROC) curves were used to compare the different risk scores. The ROC curve shows the sensitivity and specificity that correspond to each possible cut-off for the risk score. The validity of different diagnostic strategies (the existing STI management guidelines, diagnosis based on symptoms or signs alone, and diagnosis based on a risk score) was assessed by measuring sensitivity, specificity, positive and negative likelihood ratios (LR+ and LR-) and positive and negative predictive values (PPV and NPV). The LCR-based laboratory diagnosis of cervical infection was used as the reference standard. In the evaluation and comparison of diagnostic strategies, we present two cut-offs for the risk scores, taken at a sensitivity of minimum 0.40 and 0.70 .

The study was approved by ethical committees in Botswana and in Norway.

\section{Results}

Of the 703 women, 67 (10\%) had laboratory-confirmed cervical infection: 51 (8\%) were infected with $C$ trachoma- 
Table I: Three levels of risk scores: Variables included and their respective weights

\begin{tabular}{|c|c|c|c|c|}
\hline Variables included & & $\begin{array}{c}\text { Sociodemographic score } \\
\text { Weight* }\end{array}$ & $\begin{array}{c}\text { Clinical score } \\
\text { Weight }\end{array}$ & $\begin{array}{c}\text { Microscopy score } \\
\text { Weight }\end{array}$ \\
\hline \multicolumn{5}{|l|}{ Sociodemographic factors } \\
\hline \multirow[t]{3}{*}{ Age } & $<20$ & 21 & 24 & 24 \\
\hline & $20-29$ & 13 & 14 & 14 \\
\hline & $30+$ & 0 & 0 & 0 \\
\hline \multirow[t]{3}{*}{ Education } & Primary school & 10 & 12 & 11 \\
\hline & Junior secondary school & 6 & 7 & 6 \\
\hline & Senior secondary or higher & 0 & 0 & 0 \\
\hline \multirow[t]{3}{*}{ Length of relationship } & I year or less & 5 & - & - \\
\hline & Between I and 2 years & 2 & - & - \\
\hline & 2 years and more & 0 & - & - \\
\hline \multirow[t]{2}{*}{ Marital status } & Unmarried & 12 & - & - \\
\hline & Married & 0 & - & - \\
\hline \multicolumn{5}{|l|}{ Clinical factors } \\
\hline \multirow[t]{2}{*}{ Amount of discharge } & Moderate/profuse & - & 2 & 2 \\
\hline & Scarce & - & 0 & 0 \\
\hline \multirow[t]{2}{*}{ Thin/runny discharge } & Yes & - & 8 & 8 \\
\hline & No & - & 0 & 0 \\
\hline \multirow[t]{2}{*}{ Smelly discharge } & Yes & - & 5 & 4 \\
\hline & No & - & 0 & 0 \\
\hline \multirow[t]{2}{*}{ Cervix abnormal } & Yes & - & 3 & 2 \\
\hline & No & - & 0 & 0 \\
\hline \multicolumn{5}{|l|}{ Microscopy results } \\
\hline \multirow[t]{4}{*}{ White blood cell count in cervical smear } & $3-4+$ & - & - & 14 \\
\hline & $2+$ & - & - & 10 \\
\hline & $1+$ & - & - & 7 \\
\hline & No/few & - & - & 0 \\
\hline Cut-off at $40 \%$ sensitivity & & Score $>32$ & Score $>28$ & Score $>36$ \\
\hline Cut-off at $70 \%$ sensitivity & & Score $>30$ & Score $>21$ & Score $>29$ \\
\hline
\end{tabular}

*The log of the OR from the correspondent multiple logistic regression analysis for each of the variables, multiplied by 10 and rounded to the nearest whole number

tis, and 21 (3\%) with $N$ gonorrhoea. T vaginalis was identified in 131 (19\%) women and bacterial vaginosis in 268 (38\%) women. Candida species were identified by microscopy and/or culture in 416 (59\%) of the women. A total of $561(80 \%)$ of the antenatal care attendees had one or more of these five reproductive tract infections.

\section{Subjective symptoms and clinical signs}

In spite of the high prevalence of cervical and vaginal infections in this study, few women confirmed symptoms when probed. Complaints of vaginal discharge were elicited from 119 (17\%) of the women and lower abdominal pain from 58 (8\%). Vaginal discharge was the most common clinical sign; candidalike discharge was found in 81 $(12 \%)$ and other abnormal discharge was found in 227 (32\%) of the women.

\section{Factors associated with $\mathbf{C}$ trachomatis andlor $\mathbf{N}$ gonorrhoeae}

Demographic, behavioural, and obstetric factors; symptoms, signs, and simple laboratory tests; and their association with $C$ trachomatis and/or $N$ gonorrhoeae infection are shown in Table 2. Age was the strongest predictor of cervical infection. The prevalence of infection was highest among teenagers (22\%, 95\% confidence interval (CI): 13 to 32), whereas two-thirds of the infections were within the largest age group: women 20-29 years. None of the evaluated symptoms predicted cervical infection. Symptoms of vaginal discharge or lower abdominal pain were therefore not included in any of the risk scores. There were $65(9 \%)$ women who reported believing that they had a genital illness, but the prevalence of cervicitis was not significantly higher in this group ( $\mathrm{OR}=1.6,95 \% \mathrm{CI}$ : 0.8 to 3.4). Of clinical findings, vaginal (excluding candida-like) discharge was significantly associated with increased prevalence of cervicitis (OR $=1.8,95 \% \mathrm{CI}$ : 1.1 to 3.0). Several discharge characteristics (thin, smelly, foamy and increased amounts) were also significantly associated with cervical infection. Two laboratory results were associated with cervicitis; white blood cells in the cervical smear, and infection with $T$ vaginalis.

The factors which were independently associated with cervical infection are shown in Table 3. 
Table 2: Univariate analyses on risk factors for cervicitis ( $C$ trachomatis and/or $N$ gonorrhoeae) among 703 antenatal care attendees in Gaborone, Botswana

$\begin{array}{cccc}\text { No. Women with cervicitis } & \text { Odds ratio } & \text { Confidence interval } & \text { p-value } \\ \text { No. } & (\%) & (95 \%)\end{array}$

\section{Sociodemographic factors}

Age groups

$$
<20
$$

20-29

$30+$

Education

Primary school or less

Junior secondary school

Senior secondary or higher

Marital status

Married

Unmarried

Partners last 12 months

One partner

Two or more

Time in relationship

One year or less

I to 2 years

$>2$ years

\section{Subjective symptoms}

Vaginal discharge

$$
\text { No }
$$

$$
\text { Yes }
$$

Lower abdominal pain

$$
\begin{aligned}
& \text { No } \\
& \text { Yes }
\end{aligned}
$$

Thinks she has an infection

No
Yes

\section{Clinical signs}

Vaginal discharge
Negative

Candida-like discharge

Negative
Positive

$\begin{array}{ll}76 & 17 \\ 432 & 44 \\ 195 & 6\end{array}$

$\begin{array}{ll}168 & 17 \\ 310 & 36 \\ 225 & 14\end{array}$

0.008

0.000

0.004

0.620

0.160
(22)

(3)

(6)

1.2

0.6

(2)

(II)

6.9

1.7-28.7
9.1

3.6

I
3.4-24. 1

I.5-8.5

$0.6-2.2$

$0.3-1.2$

(10)

(9)

(7)

2.5

1.7

I
$0.3-3.3$

1.4-4.6

$0.9-3.2$

$\begin{array}{ll}118 & 19 \\ 137 & 16\end{array}$

0.976

0.003

0.094
$584 \quad 55$

$119 \quad 12$

650

53

638

65

9

(9)

(10)

(10)

(8)
.1

$0.6-2.1$

$0.3-2.2$

0.8

I

1.6

$0.8-3.4$

0.217

0.822

0.610

0.610
$476 \quad 37$

$227 \quad 30$

622
61
(8)

(II)

(10)
I. $1-3.0$

0.023 
Table 2: Univariate analyses on risk factors for cervicitis ( $C$ trachomatis and/or $N$ gonorrhoeae) among 703 antenatal care attendees in Gaborone, Botswana (Continued)

\begin{tabular}{|c|c|c|c|c|c|c|}
\hline Positive & 81 & 5 & (6) & 0.6 & $0.2-1.5$ & 0.279 \\
\hline \multicolumn{7}{|c|}{ Moderate or profuse discharge } \\
\hline Negative & 447 & 34 & (8) & 1 & & \\
\hline Positive & 256 & 33 & $(13)$ & 1.8 & $1.1-3.0$ & 0.023 \\
\hline \multicolumn{7}{|c|}{ Yellow discharge } \\
\hline Negative & 438 & 38 & (9) & 1 & & \\
\hline Positive & 265 & 29 & (II) & 1.3 & $0.8-2.2$ & 0.322 \\
\hline \multicolumn{7}{|c|}{ Thin/runny discharge } \\
\hline Negative & 615 & 48 & (8) & I & & \\
\hline Positive & 88 & 19 & $(22)$ & 3.3 & $1.8-5.9$ & 0.000 \\
\hline \multicolumn{7}{|c|}{ Foamy discharge } \\
\hline Negative & 590 & & & I & & \\
\hline Positive & 113 & 19 & $(17)$ & 2.3 & $1.3-4.1$ & 0.005 \\
\hline \multicolumn{7}{|c|}{ Smelly discharge } \\
\hline Negative & 659 & 58 & (9) & I & & \\
\hline Positive & 44 & 9 & $(21)$ & 2.7 & $1.2-5.8$ & 0.014 \\
\hline \multicolumn{7}{|c|}{ Cervical bleeding/erythroplaquia } \\
\hline Negative & 520 & 45 & (9) & I & & \\
\hline Positive & 183 & 22 & $(12)$ & 1.4 & $0.8-2.5$ & 0.184 \\
\hline \multicolumn{7}{|c|}{ Laboratory analyses } \\
\hline \multicolumn{7}{|c|}{ Urine stix (nitritis/leucocytes) } \\
\hline Negative & 609 & 59 & $(10)$ & I & & \\
\hline Positive & 94 & 8 & (9) & 0.9 & $0.4-1.9$ & 0.718 \\
\hline \multicolumn{7}{|c|}{ WBC in cervical smear } \\
\hline None/few & 124 & 5 & (4) & I & & \\
\hline $1+$ & 267 & 22 & (8) & 2.1 & $0.8-5.8$ & 0.135 \\
\hline $2+$ & 171 & 18 & (II) & 2.8 & I.0-7.8 & 0.048 \\
\hline $3-4+$ & 140 & 22 & $(16)$ & 4.4 & $1.6-12.1$ & 0.004 \\
\hline \multicolumn{7}{|c|}{ Candida (microscopy or culture) } \\
\hline Negative & 287 & 26 & (9) & I & & \\
\hline Positive & 416 & 41 & $(10)$ & 1.1 & $0.7-1.8$ & 0.724 \\
\hline \multicolumn{7}{|l|}{ Trichomoniasis } \\
\hline Negative & 571 & 41 & (7) & I & & \\
\hline Positive & 132 & 26 & $(20)$ & 3.2 & $1.9-5.4$ & 0.000 \\
\hline \multicolumn{7}{|c|}{ Bacterial vaginosis (BV) } \\
\hline Negative & 435 & 40 & (9) & I & & \\
\hline Positive & 268 & 27 & $(10)$ & 1.1 & $0.7-1.9$ & 0.700 \\
\hline
\end{tabular}


Table 3: Univariate and multiple logistic regression analysis of risk factors for cervicitis ( $C$ trachomatis and/or $N$ gonorrhoeae) among 703 antenatal care clients in Gaborone, Botswana

\begin{tabular}{|c|c|c|c|c|c|c|}
\hline & \multicolumn{2}{|c|}{ Total women } & \multicolumn{2}{|c|}{ Women with cervicitis } & \multicolumn{2}{|c|}{ Multiple logistic regression } \\
\hline & No. & $(\%)$ & No. & (\%) & Odds ratio & $\mathrm{p}$-value \\
\hline \multicolumn{7}{|l|}{ Age groups } \\
\hline$<20$ & 76 & (II) & 17 & $(22)$ & $10.5(3.59-30.72)$ & 0.000 \\
\hline $20-29$ & 432 & $(62)$ & 44 & (10) & $4.0(1.60-10.10)$ & 0.003 \\
\hline $30+$ & 195 & (28) & 6 & (3) & I & \\
\hline \multicolumn{7}{|l|}{ Education } \\
\hline Primary school or less & 168 & $(24)$ & 17 & $(10)$ & 1 & \\
\hline Junior secondary school & 310 & $(44)$ & 36 & $(12)$ & $0.6(0.31-1.23)$ & 0.168 \\
\hline Senior secondary or higher & 225 & (32) & 14 & $(6)$ & $0.4(0.16-0.80)$ & 0.013 \\
\hline \multicolumn{7}{|l|}{ Thin/runny discharge } \\
\hline No & 615 & (87) & 48 & (8) & 1 & \\
\hline Yes & 88 & (13) & 19 & $(22)$ & $2.1(1.06-4.24)$ & 0.035 \\
\hline \multicolumn{7}{|l|}{ WBC in cervical smear } \\
\hline None/few & 124 & $(18)$ & 5 & (4) & 1 & \\
\hline $1+$ & 267 & (38) & 22 & (8) & $2.0(0.72-5.52)$ & 0.188 \\
\hline $2+$ & $17 \mid$ & (24) & 18 & (II) & $2.7(0.92-7.6 \mathrm{I})$ & 0.070 \\
\hline $3-4+$ & 140 & (20) & 22 & (16) & $3.7(1.31-10.66)$ & 0.014 \\
\hline
\end{tabular}

\section{Syndromic management and screening for cervical infections}

The sociodemographic, clinical, and microscopy-based risk scores performed similar in the management of $N$ gonorrhoeae and $C$ trachomatis infection, as illustrated with their ROC-curves (Figure 1). The diagnostic accuracy of the risk scores did not increase significantly when detailed information from the clinical examination and subsequently the microscopy results were added to the sociodemographic risk factors.

Table 4 presents the evaluated options for the diagnosis of $C$ trachomatis and $N$ gonorrhoeae in antenatal care in the absence of specific diagnostic tests: the syndromic algorithm, symptoms, signs, and the three risk scores. The VDS algorithm did not identify women with $C$ trachomatis and $N$ gonorrhoeae in our study population (positive likelihood ratio (LR+) 1.1, 95\% CI: 0.6 to 1.9$)$. Symptoms of vaginal discharge or lower abdominal pain in pregnancy proved inappropriate as an entry point to the VDS algorithm, with a LR+ of 0.94 (95\% CI: 0.6-1.5). The current practice of clinical screening for signs of vaginal discharge (excluding candida-like discharge) also had low discriminative ability (LR+ 1.5, $95 \%$ CI 1.1-1.9).

All risk scores suffered from the choice between low sensitivity and low specificity. With a cut-off taken at an acceptable sensitivity of minimum 0.7 , the risk score based on sociodemographic factors identifies 50 (75\%) and misses 17 (25\%) of the 67 cervical infections. Per true case treated, six pregnant women would be prescribed multiple antibiotic regimens unnecessarily. With a cut-off at a sensitivity of 0.4 , the sociodemographic risk score identifies only 29 (43\%) of the cervical infections. The majority of the cervical infections would remain untreated, and although over-treatment is reduced, four pregnant women would still be unnecessary treated with multiple antibiotics per infected women. The more comprehensive clinical and microscopy risk scores show similar results.

\section{Discussion}

Pregnant women are usually considered to be a low-risk population, but among antenatal care attendees in Botswana, the burden of reproductive tract infections is very high. The prevalence of cervical infections is $10 \%$, and most of the infected women go undetected through normal antenatal care services. Published studies of STIs among pregnant women in other countries in sub-Saharan Africa show similar trends in the prevalence of cervical infections. In our study, $8 \%$ have a $C$ trachomatis infection, compared to rates between $6 \%$ in Tanzania and $13 \%$ in Cape Verde $[13,22]$. Gonorrhea is found in $3 \%$ of the women, compared to rates that range from $2 \%$ in Gabon to $8 \%$ in South Africa $[16,21]$. Although difficult to measure, it is likely that complications and sequelae due to these infections among pregnant women and their infants in sub-Saharan Africa are substantial.

\section{Syndromic approach}

Elicited symptoms of increased discharge or lower abdominal pain are not predictive of cervical infection in antenatal attendees in Botswana. These symptoms are non-specific; they are common in pregnancy, and their association with cervical infections is even lower among pregnant than among non-pregnant women [23]. The 


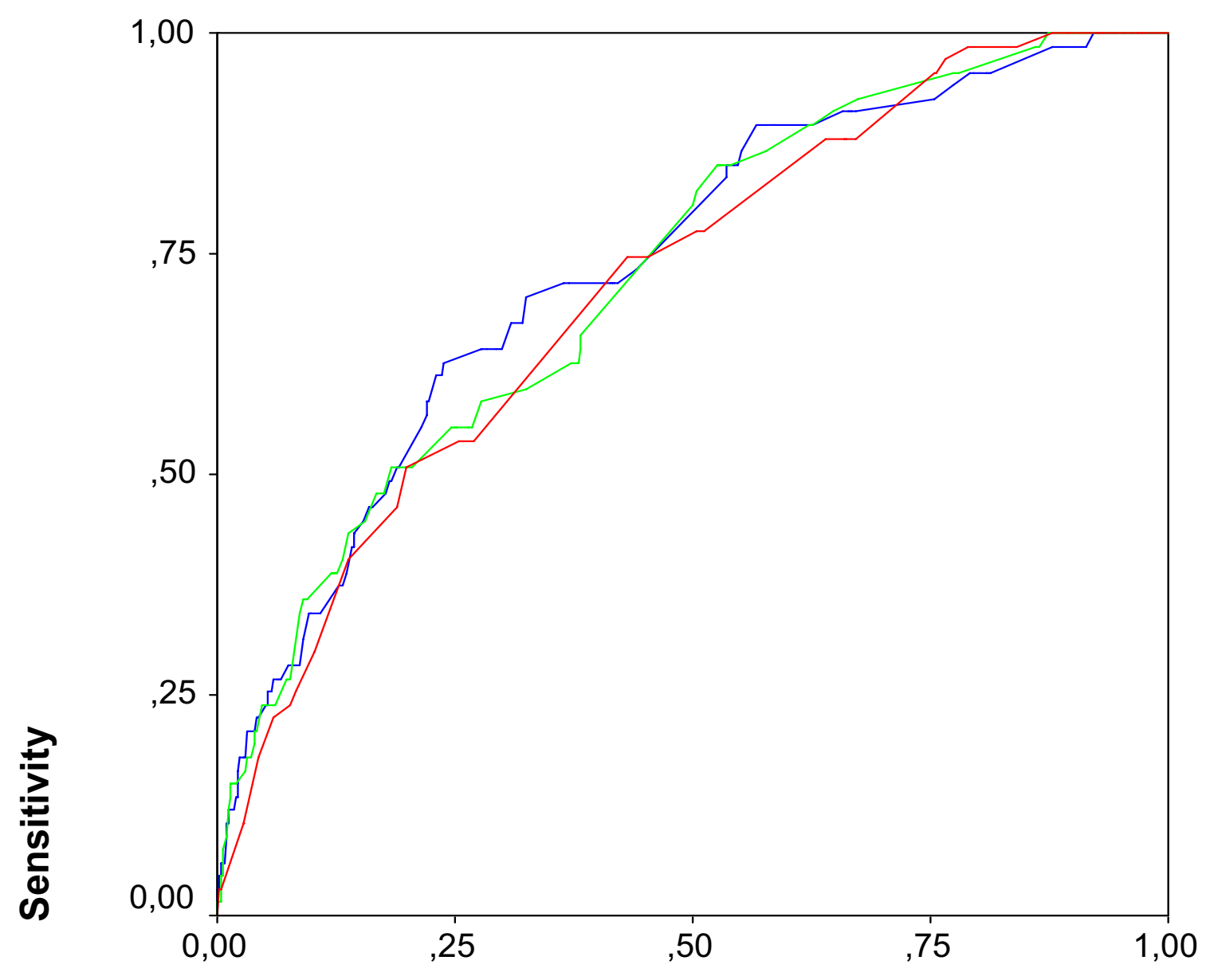

\section{1 - Specificity}

Sociodemographic risk score. Area under the curve 0.71 (0.65 to 0.78$)$

Risk factors included: Age, education, marital status, length of time in current relationship

Clinical risk score. Area under the curve 0.73 (0.67 to 0.79$)$

Risk factors included: Age, education, specific clinical signs

Microscopy risk score. Area under the curve 0.74 (0.68 to 0.80$)$

Risk factors included: Age, education, specific clinical signs and microscopy results of cervical smear

\section{Figure I}

Receiver Operating Characteristics (ROC) curves for three levels of risk scores (sociodemographic, clinical and microscopy risk scores). The risk scores are based on multiple logistic regression analyses and used as a screening tool to identify $N$ gonorrhoeae and $C$ trachomatis. The risk scores are applied retrospectively on 703 antenatal care attendees in Gaborone, Botswana. 
Table 4: Diagnostic strategies to identify infection with Chlamydia trachomatis and/or Neisseria gonorrhoeae in 703 antenatal care attendees in Botswana.

\begin{tabular}{|c|c|c|c|c|c|c|c|c|c|c|}
\hline & \multicolumn{2}{|c|}{ Positive on assessment } & \multicolumn{2}{|c|}{ Cervical infection } & \multirow[t]{2}{*}{ Sensitivity } & \multirow[t]{2}{*}{ Specificity } & \multirow[t]{2}{*}{ LR+* } & \multirow[t]{2}{*}{ LR- } & \multirow[t]{2}{*}{ PPV } & \multirow[t]{2}{*}{ NPV } \\
\hline & $\mathrm{n}$ & $(\%)$ & $\mathrm{N}$ & $(\%)$ & & & & & & \\
\hline \multicolumn{11}{|l|}{ Symptoms and signs } \\
\hline VDS algorithm & 104 & $(15)$ & II & $(\mathrm{II})$ & 0.16 & 0.85 & $1.12(0.63-1.92)$ & 0.98 & 0.11 & 0.91 \\
\hline Symptoms alone: VD and/or LAP & 155 & $(22)$ & 14 & (9) & 0.21 & 0.78 & $0.94(0.57-1.49)$ & 1.02 & 0.09 & 0.90 \\
\hline Signs alone: VD (excl. candidiasis) & 227 & $(32)$ & 30 & (13) & 0.45 & 0.69 & $1.45(1.06-1.89)$ & 0.78 & 0.13 & 0.92 \\
\hline \multicolumn{11}{|c|}{ Risk scores†, sensitivity minimum 0.7} \\
\hline Sociodemographic risk score & 327 & $(47)$ & 50 & $(15)$ & 0.75 & 0.56 & $1.71(1.42-1.99)$ & 0.45 & 0.15 & 0.96 \\
\hline Clinical risk score & 372 & (53) & 54 & $(15)$ & 0.81 & 0.50 & $1.61(1.37-1.83)$ & 0.39 & 0.15 & 0.96 \\
\hline Microscopy risk score & 273 & (39) & 51 & (19) & 0.76 & 0.65 & $2.18(1.80-2.55)$ & 0.37 & 0.19 & 0.96 \\
\hline \multicolumn{11}{|l|}{ Risk scores, sensitivity minimum 0.4} \\
\hline Sociodemographic risk score & 156 & $(22)$ & 29 & $(19)$ & 0.43 & 0.80 & $2.17(1.55-2.91)$ & 0.71 & 0.19 & 0.93 \\
\hline Clinical risk score & 117 & $(17)$ & 29 & $(25)$ & 0.43 & 0.86 & $3.13(2.20-4.30)$ & 0.66 & 0.25 & 0.94 \\
\hline Microscopy risk score & 116 & (17) & 29 & $(25)$ & 0.43 & 0.86 & $3.16(2.22-4.34)$ & 0.66 & 0.25 & 0.94 \\
\hline
\end{tabular}

$\mathrm{LR}+=$ positive likelihood ratio; $\mathrm{LR}-$ = negative likelihood ratio; $\mathrm{PPV}=$ positive predictive value; NPV = negative predictive value; VDS = vaginal discharge syndrome;

LAP = lower abdominal pain; VD = vaginal discharge

$*$ The positive likelihood ratios are calculated with $95 \%$ confidence interval.

†Risk factors included in each risk score are described in Table I

VDS algorithm is used extensively to diagnose cervical infections in antenatal care in Botswana [24], but our results show that this management is no better than random treatment.

To use the genital examination at the first antenatal care visit as a clinical screening tool for cervical infections is also unadvisable. According to the newly revised VDS algorithm in Botswana, symptoms or signs of yellow discharge are risk factors which should lead to treatment for cervical infections. In our study among antenatal care attendees, neither symptoms nor signs of yellow discharge are associated with cervical infection. In pregnancy, symptoms or signs of vaginal discharge in general, yellow discharge, or other specific discharge characteristics should not be used as criteria for treating $C$ trachomatis and $N$ gonorrhoeae.

Other studies from sub-Saharan Africa conclude that case management with the vaginal discharge syndrome has poor discriminatory ability in the diagnosis of cervicitis [25-27]. Several reviewers [28-30] emphasise that the syndromic approach should not be used as a screening tool for $N$ gonorrhoeae and $C$ trachomatis. Our study concurs with a substantial body of knowledge indicating that the syndromic approach should be used neither as a case management of symptomatic women nor as a clinical screening tool to identify $C$ trachomatis and $N$ gonorrhoeae in antenatal care attendees in sub-Saharan Africa.

\section{Screening strategies}

Despite extensive analyses, all computed risk scores were of limited value as screening tools in antenatal care attendees. They had poor discriminative ability, even in the study population in which they were computed and adapted to under optimal conditions. As the syndromic approach, the risk scores also resulted in a large number of undetected cervical infections and substantial overtreatment. Additionally, notification and treatment of sexual partners, an essential element of STI management, is difficult to justify when the majority of the identified women do not have an STI [8]. A substantial improvement of the management of cervical infections in antenatal care in developing countries seems impossible without specific diagnostic tests.

The development of simple, rapid tests for $C$ trachomatis and $N$ gonorrhoeae has been a high priority since the $1990 \mathrm{~s}$ [9-11]. Major progress has recently been made, and several tests for $C$ trachomatis and $N$ gonorrhoeae are now on the market [7,32]. The Sexually Transmitted Diseases Diagnostics Initiative at the WHO has begun a programme to field test and systematically evaluate these simple, affordable rapid tests $[32,33]$. So far, available tests are found to be specific $(>90 \%)$, but with a variable sensitivity (25-85\%) [34-36]. In Botswana, the health system is relatively well functioning, and this country could well serve as an exploratory site for the use of rapid tests for $C$ trachomatis and $N$ gonorrhoeae. Through the prevention of mother-to-child transmission of HIV programme, all health posts and clinics have lay workers who perform rapid tests for HIV. Simple tests for cervical infections performed by clinicians or lay workers may prove a feasible contribution to the improvement of diagnosis and the reduction of the disease burden of these conditions in this and similar settings.

Consistent with established knowledge on STI epidemiology $[6,31]$, youth is the single factor most strongly associated with $C$ trachomatis and/or $N$ gonorrhoeae in our study 
population. Thus age can be useful as a screening tool in the traditional sense, to minimise the number of standard diagnostic tests by identifying people with a higher-thanaverage prevalence of infection [29]. If it were decided in Botswana to introduce screening for cervical infections with rapid tests in the antenatal care, selective screening of younger women should be considered.

\section{Conclusion}

Although the vaginal discharge syndrome does not discriminate between infected and uninfected women, the algorithm is in extensive use to diagnose and treat $C$ trachomatis and $N$ gonorrhoeae among antenatal care attendees in Botswana. Unfortunately, risk scores do not appear to improve the management of cervical infections in pregnancy substantially. To diagnose and treat asymptomatic cervical infections, and to reduce the massive overtreatment in the syndromic management, specific diagnostic tests are necessary. Screening for cervical infections in pregnant women is an essential public health measure, and rapid tests will hopefully be available in developing countries within a few years. In the temporary absence of such tests, health authorities in sub-Saharan Africa should consider reallocating their resources to other STI measures rather than diagnosing and treating gonorrhoea and chlamydia inadequately in antenatal care.

\section{Abbreviations}

STI, sexually transmitted infection; VDS, vaginal discharge syndrome; PMN/HPF, polymorphonuclear leukocutes per high power field; OR, odds ratio; ROC, receiver operating characteristics; LR+ and LR-, positive and negative likelihood ratios; PPV and NPV, positive and negative predictive value; $\mathrm{CI}$, confidence interval.

\section{Competing interests}

The author(s) declare that they have no competing interests.

\section{Authors' contributions}

MR contributed to the study design, was responsible for data collection and data analysis, and drafted the manuscript. MRa contributed to the study design and to formal and organisational aspects of the study. MV contributed to the study design, and led and performed the majority of the laboratory work. JS and PH supervised the study. All authors read and approved the final manuscript.

\section{Acknowledgements}

The project was supported by the Health Sector Agreement between Norway and Botswana. The authors want to thank the Health Research Unit, Ministry of Health, for the valuable contribution to the formal and organisational aspects of the study. We also want to thank the staff at the Government Clinics and at The National Health Laboratory for their cooperation during the field work and Magne Thoresen, University of Oslo, Norway, for statistical review.

\section{References}

I. Over M, Piot P: HIV infection and sexually transmitted diseases. In Disease control priorities in developing countries Edited by: Jamison DT, Mosley WH, Measham AR, Bobadilla JS. Oxford University Press; 1993:455-527.

2. Mullick S, Watson-Jones D, Beksinska M, Mabey D: Sexually transmitted infections in pregnancy: prevalence, impact on pregnancy outcomes, and approach to treatment in developing countries. Sex Transm Infect 2005, 81:294-302.

3. Sexton J, Garnett G, Rottingen JA: Metaanalysis and metaregression in interpreting study variability in the impact of sexually transmitted diseases on susceptibility to HIV infection. Sex Transm Dis 2005, 32:351-357.

4. UNAIDS/WHO: Consultation on STD interventions forpreventing HIV: what is the evidence? Geneva 2000 [http://www.who.int/hiv/pub/sti/ pubevidence/en/].

5. WHO: Guidelines for the management of sexually transmitted infections. Geneva $2003 \quad$ [http://whqlibdoc.who.int/publications/2003/ 9241546263.pdf].

6. Brabin L: Clinical management and prevention of sexually transmitted diseases: a review focusing on women. Acta Trop 2000, 75:53-70.

7. Vuylsteke B: Current status of syndromic management of sexually transmitted infections in developing countries. Sex Transm Infect 2004, 80:333-334.

8. Mayaud P, Mabey D: Approaches to the control of sexually transmitted infections in developing countries: old problems and modern challenges. Sex Transm Infect 2004, 80: I74-I82.

9. Vuylsteke B, Laga M, Alary M, Gerniers MM, Lebughe JP, Nzila N, Behets F, Van Dyck E, Piot P: Clinical algorithms for the screening of women for gonococcal and chlamydial infection: evaluation of pregnant women and prostitutes in Zaire. Clin Infect Dis 1993, 1 7:82-88.

10. Mayaud P, Grosskurth H, Changalucha J, Todd J, West B, Gabone R, Senkoro K, Rusizoka M, Laga M, Hayes R: Risk assessment and other screening options for gonorrhoea and chlamydial infections in women attending rural Tanzanian antenatal clinics. Bull World Health Organ 1995, 73:621-630.

II. Hylton-Kong T, Brathwaite AR, Del Rosario GR, Kristensen S, Kamara P, Jolly PE, Hook EW, Figueroa JP, Vermund SH: Marginal validity of syndromic management for reproductive tract infections among pregnant women in Jamaica. Int J STD AIDS 2004, I 5:371-375.

12. Wasserheit JN, Holmes KK: Reproductive tract infections: Challenges for international health policy, programs, and research. In Reproductive tract infections: Global impact and priorities for women's reproductive health Edited by: Germain A, Holmes KK, Piot P, Wasserheit JN. New York: Plenum Press; 1992: I0-13.

13. Mayaud P, Uledi E, Cornelissen J, ka-Gina G, Todd J, Rwakatare M, West B, Kopwe L, Manoko D, Grosskurth H, Hayes R, Mabey D: Risk scores to detect cervical infections in urban antenatal clinic attenders in Mwanza, Tanzania. Sex Transm Infect 1998:39-46.

14. Mulanga-Kabeya C, Morel E, Patrel D, Delaporte E, Bougoudogo F, Maiga YI, Diawara Z, Ndoye I, Garangue S, Henzel D: Prevalence and risk assessment for sexually transmitted infections in pregnant women and female sex workers in Mali: is syndromic approach suitable for screening? Sex Transm Infect 1999, 75:358-359.

15. Schneider H, Coetzee DJ, Fehler HG, Bellingan A, Dangor Y, Radebe $F$, Ballard RC: Screening for sexually transmitted diseases in rural South African women. Sex Transm Infect 1998: I47-I 52.

16. Bourgeois A, Henzel D, Dibanga G, Malonga-Mouelet G, Peeters M, Coulaud JP, Fransen L, Delaporte E: Prospective evaluation of a flow chart using a risk assessment for the diagnosis of STDs in primary healthcare centres in Libreville, Gabon. Sex Transm Infect 1998: I28-132.

17. Botswana Ministry of Health: Management of sexually transmitted infections: Reference manual for health workers. Gaborone 2005.

18. Bailey G, Ryan C, Rahman M: Sexually transmitted infections in Botswana: Prevalence of infection and evaluation of syndromic management algorithms. Gaborone 2004.

19. Botswana Ministry of Health: Guidelines for antenatal care and the management of obstetric emergencies and prevention of mother-to-child transmission of HIV. Gaborone 2005. 
20. Nugent RP, Krohn MA, Hillier SL: Reliability of diagnosing bacterial vaginosis is improved by a standardized method of gram stain interpretation. J Clin Microbiol I99I, 29:297-30I.

21. Sturm AW, Wilkinson D, Ndovela N, Bowen S, Connolly C: Pregnant women as a reservoir of undetected sexually transmitted diseases in rural South Africa: implications for disease control. Am J Public Health 1998, 88: I243-1245.

22. Wessel HF, Herrmann B, Dupret A, Moniz F, Brito C, Bergstrom S: Genital infections among antenatal care attendees in Cape Verde. Afr J Reprod Health 1998, 2:32-40.

23. Hudson CP: Syndromic management for sexually transmitted diseases: back to the drawing board. Int J STD AIDS 1999, 10:423-434.

24. Romoren M, Rahman M, Sundby J, Hjortdahl P: Chlamydia and gonorrhoea in pregnancy: effectiveness of diagnosis and treatment in Botswana. Sex Transm Infect 2004, 80:395-400.

25. Mayaud P, ka-Gina G, Cornelissen J, Todd J, Kaatano G, West B, Uledi E, Rwakatare M, Kopwe L, Manoko D, Laga M, Grosskurth H, Hayes $\mathrm{R}$, Mabey D: Validation of a WHO algorithm with risk assessment for the clinical management of vaginal discharge in Mwanza, Tanzania. Sex Transm Infect 1998:77-84.

26. Costello Daly C, Wangel AM, Hoffman IF, Canner JK, Lule GS, Lema VM, Liomba NG, Dallabetta GA: Validation of the WHO diagnostic algorithm and development of an alternative scoring system for the management of women presenting with vaginal discharge in Malawi. Sex Transm Infect 1998:50-58.

27. Alary M, Baganizi E, Guedeme A, Padonou F, Davo N, Adjovi C, van Dyck E, Germain M, Joly J, Mahony JB: Evaluation of clinical algorithms for the diagnosis of gonococcal and chlamydial infections among men with urethral discharge or dysuria and women with vaginal discharge in Benin. Sex Transm Infect 1998:44-49.

28. Pettifor A, Walsh J, Wilkins $V$, Raghunathan $P$ : How effective is syndromic management of STDs?: A review of current studies. Sex Transm Dis 2000, 27:37I-385.

29. Sloan NL, Winikoff B, Haberland N, Coggins C, Elias C: Screening and syndromic approaches to identify gonorrhea and chlamydial infection among women. Stud Fam Plann 2000, 3I:55-68.

30. Dallabetta GA, Gerbase AC, Holmes KK: Problems, solutions, and challenges in syndromic management of sexually transmitted diseases. Sex Transm Infect 1998: I-I I.

31. Cates W Jr: Contraception, unintended pregnancies, and sexually transmitted diseases: why isn't a simple solution possible? Am J Epidemiol 1996, I43:3 II-318.

32. Mabey D, Peeling RW: Rapid diagnostic tests for sexually transmitted infections. IPPF Med Bull 2002, 36: I-3.

33. Sexually Transmitted Diseases Diagnostics Initiative (SDI) [http://www.who.int/std diagnostics]

34. Vickerman P, Watts C, Peeling RW, Mabey D, Alary M: Modelling the cost effectiveness of rapid point of care diagnostic tests for the control of HIV and other sexually transmitted infections among female sex workers. Sex Transm Infect 2006 82:403-4I2.

35. Yin Y-P, Peeling RW, Chen X-S, Gong K-L, Zhou H, Gu W-M, Zheng H-P, Wang Z-S, Yong G, Cao W-L, Shi M-Q, Wei W-H, Dai X-Q, Gao X, Chen Q, Mabey D: Clinic-based evaluation of Clearview Chlamydia MF for detection of Chlamlydia trachomatis in vaginal and cervical specimens from women at high-risk in China. Sex Transm Infect 2006, 82:33-37.

36. Benzaken AS, Galban EG, Antunes W, Dutra JC, Peeling RW, Mabey $D$, Salama $A$ : Diagnosis of gonococcal infection in high risk women using a rapid test. Sex Transm Infect 2006:26-28.

\section{Pre-publication history}

The pre-publication history for this paper can be accessed here:

http://www.biomedcentral.com/1471-2334/7/27/prepub
Publish with Bio Med Central and every scientist can read your work free of charge

"BioMed Central will be the most significant development for disseminating the results of biomedical research in our lifetime. "

Sir Paul Nurse, Cancer Research UK

Your research papers will be:

- available free of charge to the entire biomedical community

- peer reviewed and published immediately upon acceptance

- cited in PubMed and archived on PubMed Central

- yours - you keep the copyright

Submit your manuscript here:

http://www.biomedcentral.com/info/publishing_adv.asp
BioMedcentral 